\title{
La pena efectiva en el delito de violación impropia: un conflicto entre merecimiento y necesidad de pena (Tribunal Constitucional)
}

\author{
Comentario de Isabel Ruiz-Esquide Enríquez*
}

Comentario de sentencia del Tribunal Constitucional, Rol N 6506-19 INA, de fecha 07 de noviembre de 2019, requerimiento de inaplicabilidad por inconstitucionalidad respecto del inciso segundo del artículo $1^{\circ}$ de la Ley $\mathrm{N}^{\circ} 18216$, en proceso penal Ruc No 1500653979-0 Rit No 439-2018, seguido ante el Tribunal de Juicio Oral en lo Penal de San Bernardo, por el delito de violación impropia del artículo 362 del Código Penal, que acogió recurso. https://www.tribunalconstitucional.cl/sentencias/ busqueda-avanzada.

Considerandos del voto de mayoría que serán objeto de comentario:

[...] CuARto: Que, siguiendo esos mismos razonamientos, en esta oportunidad y aun tratándose del delito tipificado en el artículo 362 del Código Penal, acogeremos el requerimiento deducido a fs. 1 , solo teniendo en cuenta las circunstancias del caso concreto que configuran la gestión pendiente que sustentaron argumentaciones, por parte de la defensa del requirente, dotadas de fundamentación plausible, lo que, en su momento, justificó acceder a la petición formulada a fs. 166, puesto que, en este caso, no obstante la gravedad del delito, no resulta necesario adoptar, en abstracto y sin apreciación judicial, la privación efectiva de la libertad dispuesto en la sentencia condenatoria, debiendo dejar al juez de fondo la decisión acerca de su sustitución por otra forma de cumplimiento; [...]

[...] Octavo: Que, en consecuencia, no hay duda en cuanto a la gravedad de la conducta delictiva por la que se ha castigado al requirente por el Tribunal de Juicio Oral en lo Penal de San Bernardo, dado que afecta bienes jurídicos de la más alta importancia, pero, en este caso, concretar la privación efectiva de libertad, mediante la aplicación del precepto legal impugnado, no resulta una medida estrictamente necesaria, habida

* Abogada, Ex Fiscal Adjunta, Magíster en Derecho con mención en Derecho Penal, Universidad de Chile. Doctoranda en Derecho, Universidad Austral de Chile. Correo electrónico: isabelruizesquideenriquez@gmail.com 
consideración de las circunstancias del caso concreto resumidas en su lugar, por lo que estimamos procedente acoger el requerimiento de fs. 1 y que el juez de la gestión pendiente pueda resolver, con plena competencia, la eventual aplicación de penas sustitutivas. [...]

Considerando del voto disidente que será objeto de comentario:

[...] $15^{\circ}$ Que, por lo anterior, la norma introducida por la Ley $\mathrm{N}^{\circ} 19.617$ a la $\mathrm{N}^{\mathrm{o}} 18.216$ y actualmente cuestionada por la acción deducida, es proporcional a la entidad del delito que se imputa al requirente, en la eventualidad de que la sentencia condenatoria, actualmente recurrida, sea ejecutoriada.

La configuración del tipo penal supone efectuar un análisis doble: por una parte, el hecho típico que traerá como resultado una sanción y, por otro lado, la forma en que la pena ha de ser cumplida. Y en ese ámbito el legislador cuenta con un margen para tomar una decisión, en el marco de la política criminal, que será conforme a la Constitución si no excede sus límites. La opción legislativa es así idónea conforme a los fines que fueron latamente expuestos, vinculados al delito de violación realizado respecto de menores de doce años (hoy catorce años) y el bien jurídico protegido, cual es la indemnidad sexual. Asimismo es necesaria para el fin buscado y además constitucional, en el entendido de que no elimina las facultades del juez para conocer y juzgar, sino que solo dispone el cumplimiento efectivo de lo que el mismo sentenciador decida. También es proporcional en sentido estricto, por cuanto constituye una medida equilibrada y justa respecto de una persona que ha cometido un importante atentado a un ilícito que busca salvaguardar la indemnidad en el desarrollo sexual de niños y niñas, dejando a salvo el eventual acceso, posteriormente, al beneficio de la libertad condicional, cumpliendo los requisitos que se exigen para tal efecto. [...]

\section{Comentario}

El Tribunal Constitucional conoce, en sentencia rol 6506-19 que se comenta, respecto de la procedencia de penas sustitutivas para un sujeto condenado por un delito de violación impropia (Art. 362 CP), a una pena de 600 días de presidio menor en su grado medio, más accesorias legales, por el Tribunal de Juicio Oral en lo Penal de San Bernardo, el que, en uso del arbitrio judicial contemplado en las normas de determinación de pena, fijó dicha cuantía, atendida la concurrencia de dos atenuantes de responsabilidad penal: la irreprochable conducta anterior del artículo $11 \mathrm{~N}^{\circ} 6$ y la colaboración sustancial al esclarecimiento de los hechos del artículo $11 \mathrm{~N}^{\circ}$ 9, ambos del Código Penal.

La sentencia del TC acoge, en su voto de mayoría, la inaplicabilidad del artículo $1^{\circ}$ inciso segundo de la Ley $\mathrm{N}^{\circ} 18.216$, recogiendo argumentos que antes había referido a casos de Ley de Control de Armas. Lo anterior, pese a que en la especie se trata de un caso de crimen, de aquellos para los que el mismo TC había negado con anterioridad la 
procedencia del requerimiento de inaplicabilidad ${ }^{1}$. Por su parte, el voto disidente realiza un ejercicio de ponderación entre los principios constitucionales en juego y, destacando la relevancia del bien jurídico protegido en este caso -indemnidad sexual-, rechaza el recurso, resolviendo así el conflicto entre necesidad y merecimiento de pena.

Como se ha señalado, estima el voto de mayoría, que es pertinente la imposición de penas sustitutivas a un caso consumado de violación impropia. Para lo anterior, el tribunal reitera los argumentos que había desarrollado en casos anteriores sobre Ley de Control de Armas. Dichos argumentos constituyen básicamente dos líneas argumentativas distintas, y consisten en: i) el ius puniendi estatal reconoce como límites, los valores y principios consagrados en nuestra Constitución, y ii) el principio de proporcionalidad de las penas limita la severidad de estas, a la gravedad del delito o de la conducta cometida. El voto de mayoría agrega que, para el caso que nos ocupa, las circunstancias sociales y familiares del requirente hacen pertinente que el juez de la causa sea quien determine la procedencia de penas sustitutivas, inaplicando así la prohibición legal del artículo 1 inciso $2^{\circ}$ de la Ley $\mathrm{N}^{\circ} 18.216$.

Los motivos que se encuentran en el desarrollo del voto de mayoría apuntan, como he señalado, a las circunstancias específicas del caso particular, que desaconsejan la pena efectiva, en tanto esta $[\ldots .$.$] " no resulta una medida estrictamente necesaria" [\ldots]^{2}$. La sentencia, pretende dar cuenta de un conflicto constitucional entre una sanción penal de cumplimiento efectivo y las decisiones político-criminales adoptadas por el legislador en la Ley $\mathrm{N}^{\circ} 18.216$, como un conflicto entre los derechos a la dignidad humana del imputado, la igualdad ante la ley y un procedimiento justo y racional, por un lado, y el llamado "derecho a punir" cuya legitimidad depende de su orientación a la estricta protección de bienes jurídicos, por otro. Así, confronta la forma de cumplimiento de la sanción penal, estableciendo el conflicto del caso, como una contradicción, para la cual el recurso de inaplicabilidad resulta pertinente, en tanto plantea una tensión concreta entre dichos derechos y los bienes jurídicos protegidos por el legislador.

Sostiene el tribunal que en materia de inaplicabilidad por penas sustitutivas de la Ley $\mathrm{N}^{\circ}$ 18.216, ha ido desarrollando ciertos parámetros como, por ejemplo, acogerlos tratándose de casos referidos a la Ley de control de Armas $N^{0} 17.798$. En ellos ha resuelto el TC, a favor de la inaplicabilidad del artículo $1^{\circ}$ inciso segundo de la Ley $\mathrm{N}^{\circ} 18.216$, atendiendo a la dignidad humana. Indica que ello se sustenta en tanto el ius puniendi estatal reconoce en ella uno de sus límites, junto con el principio de humanidad, de forma que la privación de libertad solo ha de imponerse respecto de las conductas más graves, siempre que afecten los bienes jurídicos de la más alta importancia protegidos por el ordenamiento y cuidando siempre las finalidades de prevención especial y protección a las víctimas.

\footnotetext{
${ }^{1}$ En sentencias previas el tribunal ha estimado que, para casos de crímenes, como violación u homicidio, existe un [...] "entramado ajeno" [...], a los casos de Ley de Armas, en tanto es posible [...] "apreciar una vinculación entre la dañosidad del delito en sí con la sanción que a su respecto ha previsto el legislador” [...] Entre otras: STC de 26 de marzo de 2018, rol 4263-18, STC de 22 de enero de 2019, rol 4894-19.

${ }^{2}$ STC de 5 de noviembre de 2019, rol 7039-19 INA, considerando. 8, p.6.
} 
Estos argumentos dan cuenta de una particular forma de aplicar el principio de proporcionalidad por parte del Tribunal, como ha destacado la doctrina ${ }^{3}$, para el caso que nos ocupa, porque la sentencia hace suyos dichos argumentos, muestra cómo la confusa consideración de solo uno de los elementos de dicho principio -concretamente la necesidad del medio adoptado por el Estado para la prosecución del fin propuestolleva a resultados criticables ${ }^{4}$.

Dicho de otra forma, debido a que el TC reduce la aplicación del principio de proporcionalidad solo al elemento de necesidad de la medida, y que lo aplica comparando la medida legislativa que se impugna con otras formas de cumplimiento como medios alternativos, concluye que, tratándose de un caso en que se arriesga una pena de 600 días de presidio menor en su grado medio, no resulta necesario su cumplimiento de forma efectiva. Olvida sin embargo, el voto de mayoría, que el examen al que está llamado5, debe partir por argumentos relativos a la idoneidad de la medida, en los cuales ha de referirse a la finalidad de la medida legislativa, continuar, si procede, con argumentos referidos a la necesidad, o $[\ldots .$.$] "subprincipio del medio más benigno" [\ldots]^{6}$ en el que ha de observar los medios alternativos que permitan, en algún grado conseguir los objetivos legislativos de la medida, y luego, si procede, realizar un ejercicio de proporcionalidad en sentido estricto, en donde ha de preguntarse por la gravedad de los hechos, procurando que las consecuencias del delito guarden proporción con el delito cometido ${ }^{7}$. No refiere el voto de mayoría análisis alguno respecto de dichos elementos, ni tampoco los argumentos en orden a por qué restringe el ejercicio de proporcionalidad en sentido amplio a solo uno de sus subprincipios, ni la particular forma en que dicha medida alternativa permite realizar los objetivos del legislador para un caso de violación impropia como el que nos convoca.

Estas falencias del voto de mayoría constituyen una constante en causas de inaplicabilidad de Ley Emilia o Ley de Control de $\operatorname{Armas}^{8}$, pero resultan llamativas cuando se reproducen para casos especialmente graves, como el que ocupa al TC en esta oportunidad.

Es la particular forma de aplicación del principio de proporcionalidad, y de la interpretación del subprincipio de necesidad, la que permite comprender -sostengo- que el tribunal en su voto de mayoría no se haga cargo de la especial gravedad del hecho, ni cómo aquello influye con el fin de dirimir el conflicto constitucional que se le presenta.

${ }^{3}$ Al respecto, Grez, P. y Willenmann, J., 2019: "Un desarrollo preocupante: sobre una tendencia reciente en el control constitucional de leyes penales", Revista de Derecho (Coquimbo), 26, pp. 1 y ss. Disponible en www.https://doi.org/10.22199/issn.0718-9753-2019-0014.

${ }^{4}$ Respecto del principio de proporcionalidad en la motivación de los tribunales constitucionales, Bernal Pulido, C., 2005: El principio de proporcionalidad y los derechos fundamentales, 2005, Bogotá: Universidad del Externado, pp. 39 y ss.

${ }^{5} I d ., \mathrm{pp} .491$ y ss.

${ }^{6} I d$., p. 736.

${ }^{7}$ Mapelli, B., 2005: Las consecuencias jurídicas del delito, Navarra: Aranzadi, pp. 38 y ss.

8 Tal como refieren Grez y Willenmann, 2019, pp. 1 y ss., el TC en realiza un ejercicio de proporcionalidad sin seguir los pasos que componen dicho ejercicio ni la prevalencia lógica de ellos. 
Por su parte, el voto disidente analiza la opción legislativa de la Ley $\mathrm{N}^{\mathrm{o}}$ 18.216, como medida a la que aplicará el test de proporcionalidad. Otorga los motivos por los cuales la considera una medida idónea, atendidos los fines que se persiguen con la imposición de la pena vinculada al delito de violación impropia, y particularmente al bien jurídico protegido. Luego se pronuncia acerca de su necesidad, indicando que la misma no limita el arbitrio de la determinación judicial de la pena, sino que solo dispone el cumplimiento efectivo del quantum determinado. Finalmente, la disidencia analiza la razonabilidad de la medida, haciéndose cargo de la proporcionalidad en sentido estricto de la misma, indicando que la negativa de penas sustitutivas para el caso, ha sido contemplada por el legislador respecto de una persona que [...] "ha cometido un importante atentado a un ilícito que busca salvaguardar la indemnidad en el desarrollo sexual de niños y niñas, dejando a salvo el eventual acceso, posteriormente, al beneficio de la libertad condicional, cumpliendo los requisitos que se exigen para tal efecto" $[\ldots]^{9}$. De esta forma, el voto disidente justifica la improcedencia de pena sustitutiva rechazando el requerimiento presentado.

En mi opinión, la Ley $\mathrm{N}^{\circ} 18.216$ contiene una opción político-criminal en orden a aplicar penas sustitutivas solo en aquellos casos de conductas de menor gravedad. En ese contexto, corresponde precisamente al TC, como garante de los derechos fundamentales ${ }^{10}$, aplicar sus normas de tal forma que permita distinguir, entre aquellas conductas que admitirán una pena sustitutiva por ser de menor gravedad, de aquellas que, en cambio, ameritarán una pena efectiva, atendida su mayor lesividad, otorgando los elementos que permitan conocer qué conducta, en definitiva, ha de ser sancionada con pena efectiva.

La interpretación constitucional de la ley a la que está llamado el TC, consiste precisamente en identificar la dimensión ética sustantiva del estado constitucional de derecho que, ya que se encuentra compuesta por diversos principios, derechos y valores, conlleva de por sí, tensiones en su interior. En el caso que se comenta, el conflicto entre merecimiento y lesividad de la conducta, que se deriva de los principios de dignidad humana y libertad, debe ser resuelto entregando parámetros que permitan la comprensión de la ponderación efectuada. En este sentido, el voto disidente entrega elementos que permiten componer la "lesividad de la conducta", tales como la gravedad de la pena y la relevancia de los bienes jurídicos afectados. Dichos elementos permiten comprender la manera en que se resuelve la contradicción del caso particular. En cambio, el voto de mayoría no permite distinguir aquello, pues pondera únicamente las circunstancias concretas del caso para estimar como “innecesaria” la medida impugnada, interpretando de forma particular dicho subprincipio, restringiendo de paso la aplicación del test de proporcionalidad en sentido amplio a tan solo uno de sus elementos ${ }^{11}$.

${ }^{9}$ STC de 5 de noviembre de 2019, rol 7039-19 INA, considerando $15^{\circ}$, p. 14.

${ }^{10}$ Fernández Cruz, J., 2014: “Tribunal Constitucional y Derecho penal: un estudio crítico”, Revista de Estudios Constitucionales, Universidad de Talca, año $12 \mathrm{~N}^{\circ} 2$, p. 188.

${ }^{11}$ Mapelli, B., 2005: Las consecuencias jurídicas del delito, Navarra: Aranzadi, pp. 38 y ss. 
